\title{
Day-of-the-Week-Effects in West African Regional Stock Market
}

\author{
Aboudou Maman Tachiwou (Corresponding author) \\ S/C MAMAN - WATARA Gaouzou, Cabinet Maitre AYEVA \\ 05. BP. 769 Lomé Agbalépédogan. LOME - TOGO \\ E-mail: amtwatara@hotmail.com
}

\begin{abstract}
This paper provides the first evidence for the presence of the day of the week effects in West African regional stock market in the sample for the period September 1998 to December 2007.The observed daily patterns exhibiting lower daily means and lower standard deviations. In local currency terms, a pattern of lower returns around the middle of the week, Tuesday and then Wednesday; and a higher pattern towards the end of the week, Thursday and then Friday, are observed. The results have useful implications for international portfolio diversification. This may be of particular interest for the global investor.
\end{abstract}

Keywords: Day of the week effects, West African regional markets, Brvm

\section{Introduction}

In recent years the testing for market anomalies in stock returns has become an active field of research in empirical finance and has been receiving attention from not only in academic journals but also in the financial press. Among the more well-known anomalies are the size effect, the January effect and the day-of-the week effect. The day of the week effect is a phenomenon that constitutes a form of anomaly of the efficient capital markets theory. According to this phenomenon, the average daily return of the market is not the same for all days of the week, as we would expect on the basis of the efficient market theory. The day-of -the-week effect continues to be one of the more interesting stock market anomalies to study because the existence of significant day-of-the-week effects would be very useful for developing profitable trading strategies. Investors could buy stocks on days with abnormally low returns and sell stocks on days with abnormally high returns.

The objective of this paper is to investigate daily stock market anomalies in the West African regional stock market using its two stock index, the Brvm-10 index and Brvm-composite index, to shed some light on the degree of market efficiency in an emerging capital market. We examine daily stock market returns from September 1998 to December 2007, the period over which West African regional stock market were consistently traded on a five-day per week basis.

The paper is organized as follows: in section 2, we present overview of the literature on the day-of-the-week effect, section 3 describe the methodology and data framework of our research; section 4 gives the interpretation of the empirical results. This dissertation closes in section 5 with a conclusion.

\section{Literature Review on the Day-of-the-week effect}

Returns and how they are related with the days of the week is a popular study area in finance literature. Earlier studies have found the existence of the day of the week effect not only in the USA and other developed markets but also in the emerging markets like Malaysia, Hong Kong, Turkey. For most of the western economies, (U.S.A., U.K., Canada) empirical results have shown that on Mondays the market has statistically significant negative returns while on Fridays statistically significant positive returns. In other markets such as Japan, Australia, Singapore, Turkey and France the highest negative returns appear on Tuesdays.

The most satisfactory explanation that has been given for the negative returns on Mondays is that usually the most unfavorable news appears during the weekends. These unfavorable news influence the majority of the investors negatively, causing them to sell on the following Monday. The most satisfactory explanation that has been given for Tuesday's negative returns are that the bad news of the weekend affecting the USA's market, influence negatively some markets lagged by one day.

In most developed markets such as the USA's, the United Kingdom's and Canada's, most studies, Cross (1973), Gibbons \& Hess (1981), Keim \& Stambaugh (1984), Theobald and Price (1984), Jaffe \& Westerfield (1985), Harris (1986), Simrlock \& Starts (1986), Board and Sutcliffe (1988), and Kohers and Kohers (1995), Tang and Kwok (1997) for six indices [Dow Jones Industrial Average Index( US), Financial Times Index (UK), Nikkei Average Index (Japan), Hang Seng Index (Hong Kong), FAZ General Index (Germany) and All Ordinary Index (Australia)] and many others, have come to the conclusion that Mondays' average returns are negative and Fridays' are positive. 
In other words, the stock exchange market starts downwards and ends upwards. However, in some other studies such as Condoyanni, O'Hanlon \& Ward (1987), Solnik \& Bousqet (1990) in the French stock market; Athanassakos \& Robinson (1994) in the Canadian market, Jaffe \& Westerfield (1985) in the stock markets of Australia and Japan, Kim (1988) in the stock markets of Japan and Corea, Aggarwal \& Rivoli (1989) in the stock markets of Hong Kong, Singapore, Malaysia and Philippines, Ho (1990) in the stock markets of Australia, Hong Kong, Japan, Korea, Malaysia, New Zealand, Philippines, Singapore, Taiwan and Thailand, Wong, Hui and Chan (1992) in the markets of Singapore, Malaysia, Hong Kong and Thailand, Dubois \& Louvet (1996) in the stock markets of Japan, Australia, Agrawal and Tandon (1994) for eighteen countries and many others, the negative average returns are observed on Tuesdays. Also, for the Istanbul stock exchange there were negative average returns on Tuesdays [Aydoðan (1994), Balaban (1995), Bildik (1997) and Özmen (1997)].

On the other hand, studies on the Spanish stock market have revealed that there is no day of the week effect, [Santemases (1986), Pena (1995) and Gardeazabal and Regulez (2002)]. Solnik and Bousquet (1990) focused on the period 1978- 1987 and examined the CAC Index of Paris Bourse. Their results showed strong and persistent negative mean returns on Tuesdays. Solnik (1990) wondered whether the settlement procedure could explain the pattern of daily returns observed in previous studies of the Paris Bourse.

Dubois and Louvet (1996) re-examined the day of the week effect for the French stock market along with other markets such as the US, UK, German, Japanese, Australian and Swiss markets, during the period 1969-1992 using standard statistical approaches and moving averages. They observed that Wednesdays presented the highest return while the day with the lowest (negative) return was Monday for all the above markets except the Japanese and the Australian. The null hypothesis of the equality among the mean returns of all days of the week was rejected at the $1 \%$ confidence level. The authors concluded that probably, the different settlement systems could account for difficulties in comparing the results internationally, but could not explain the possible reasons for this anomaly in the US and the European markets they examined. If an anomaly exists in the market, the investors can take advantage of the same and adjust their buying and selling strategies accordingly to increase their returns with timing the market.

Agrawal and Tandon (1994) provide international evidence for several seasonalities in stock markets of eighteen countries (Australia, Belgium, Brazil, Canada, Denmark, France, Germany, Hong Kong, Italy, Japan, Luxembourg, Mexico, the Netherlands, New Zealand, Singapore, Sweden, Switzerland, and the UK) other than the USA. They find large, positive mean returns on Fridays and Wednesdays in most of the countries. They observe lower or negative mean returns on Mondays and Tuesdays, and higher and positive returns from Wednesday to Friday in almost all the countries.

Balaban $(1995,1996)$ reports that in the Turkish stock market for the period January 1988 to August 1994 the highest returns and the lowest standard deviations on Fridays followed by Wednesdays. He observes the lowest and negative mean returns on Tuesdays, and the highest standard deviations on Mondays. In addition, he notes that the day of the week effects change in direction and magnitude across years. Balaban (1999) claims that observed anomalies can be partly attributed to the settlements rules in the Turkish stock market. Dubois and Louvet (1996), find negative returns on Mondays and Tuesdays and positive returns on Wednesdays for eleven indices in nine countries from 1969 to 1992.

In the US stock market the mean Monday stock return has been found to be negative or significantly lower than the non-Monday return. Many studies have shown that in addition, mean stock return on Fridays is significantly high relative to other days. See for example Cross (1973), French (1980) and Jaff, Westerfield and Ma (1989), Gibbons and Hess (1981), Lakonishok and Levi (1982), Gultekin and Gultekin (1983), Rogalski (1984), Harris (1986), Lakonishok and Smidt (1988),Solnik and Basquest (1990), Dubois and Louvet (1996), Mehdian and Perry (2001), Chiaku (2006) among others document the Monday effect or other daily anomalies in the US and international stock markets.

\section{Methodology and Data}

Our data consist of daily opening and closing values for the two stock Index of West African regional markets from September 1998 to December 2007. The index data are collected from the BRVM direction, Abidjan, Cote d'Ivoire. The two indexes are Brvm-10 index and Brvm-composite index: the Brvm-composite index is a value-weighted of all stocks listed on West African regional markets and Brvm-10 index is a value-weighted of ten companies most active in the regional stock market.

Daily returns that amount to 1290 observations for the two indexes are calculated as follows:

$$
\mathrm{R}_{t}=\log \left(\mathrm{P}_{t} / \mathrm{P}_{t+1}\right) \times 100
$$


where $\mathrm{P}_{t}$ and $\mathrm{R}_{t}$ are, respectively, the closing value of stock market index and return

We run the following regression with binary dummy variables for each country to test whether there is any statistically significant difference among stock market

Returns, on different days of the week:

$$
\mathrm{R}_{t}=\sum^{5} B_{i} D_{i t}+u_{t}
$$

where $D_{1 t}=1$ if day $t$ is a Monday and 0 otherwise; $D_{2 t}=1$ if day $t$ is a Tuésday and 0 otherwise; and so on. The coefficients $B 1$ to $B 5$ are the mean returns for Monday through Friday, respectively. The stochastic error term is given by $u_{t}$.

Using the regression in equation (1), the following hypotheses are proposed and tested to determine the existence of the day-of-the-week effect in the West African Regional stock market.

$\mathrm{H}_{0 D}$ : Mean returns of each trading day are equal. (Days before and after holidays are included in the data set)

$$
(\mathrm{B} 1=\mathrm{B} 2=\mathrm{B} 3=\mathrm{B} 4=\mathrm{B} 5)
$$

$\mathrm{H}_{1 D} \quad$ At least one trading day has a significantly different mean return.

In order to test whether the distribution of stock returns actually changes across the days-of-the-week, the data are categorized into five groups (Monday through Friday) in accordance with days of the week. We test the following null hypothesis of equal mean returns across days of the week:

$$
(B 1=B 2=B 3=B 4=B 5)
$$

If the daily returns are drawn from an identical distribution, they will be expected to be equal. However, the rejection of the null hypothesis would indicate a specific observable pattern in the stock market returns, thus violation of weak-form market efficiency.

\section{Empirical Results}

Average daily returns over the trading period of 1998-2007 for the West African Regional stock market two indices with their t-values are presented in Table 1 (all days of the week are included). The both index: Brvm-10 and Brvm-Composite shows that the $\mathrm{H}_{0 D}$ can be rejected. In fact, the insignificance of all F-values in Table 1 of the West African Regional stock market two indices supports the conclusion that the distribution of returns for each day of the week might be i.i.d.

According to the results shown in Table 1, the day with the lowest return is Wednesday for Brvm-10 and Tuesday for Brvm-Composite. On the other hand, Thursday presents the highest return of the week for Brvm-Composite and Friday for Brvm-10. However, the null hypothesis of equality among the means of returns of each day of the week can be rejected at the $10 \%$ significance level. So, we can conclude that the phenomenon of the day of the week effects exist for the case of West African Regional stock market during the period of study and the Trading Time hypothesis holds.

The coefficient of variation (CV), standard deviation divided by mean return, is used as a measure of risk per unit return. The highest CV values are observed on Wednesday among days of the week. Moreover, the lowest CV values appear towards the end of the week (Thursday, Friday) returns. The lowest standard deviations returns on Mondays is not conform with the studies: Fama (1965), Gibbons and Hess (1981), Agrawal and Tandon (1994), and Balaban $(1995,1996)$. However, it is interesting to observe the lowest standard deviations returns on Tuesdays, just after Mondays with the lowest standard deviations.

\section{Further analysis for the Weekend Effect in stock market}

Miller (1988) attributes the negative returns over weekends to a shift in the broker-investor balance in decisions to buy and sell. During the week, Miller argues, investors, too busy to do their own research, tend to follow the recommendations of their brokers, recommendations that are skewed to the buy side. However, on weekends investors, free from their own work as well as from brokers, do their own research and tend to reach decisions to sell. The result is a net excess supply at Monday's opening. Miller's hypothesis is supported by evidence showing that brokers do tend to make buy recommendations, by evidence that odd-lot transactions tend to be net sales, and by data showing that odd-lot volume is particularly high and institutional volume is particularly low on Mondays. Thus, individual investors tend to sell on Mondays when the lack of institutional trading reduces liquidity.

Another explanation for the negative weekend effect is that stock prices close "too high" on Fridays or "too low" on Mondays. One variant attributes unusually high Friday closing prices to settlement delays. The delay between the trade date and the settlement date creates an interest-free loan until settlement. Friday buyers get two extra days of 
free credit, creating an incentive to buy on Fridays and pushing Friday prices up. The decline over the weekend reflects the elimination of this incentive. This hypothesis is supported by the intraweek behavior of volume and returns: Friday is the day with the greatest volume and with the most positive stock returns.

\section{Conclusions}

This study presents evidence for the existence of the day of the week effects for a recent period of time in West African Regional stock market return. The daily effects are analyzed in stock market returns of the West African Regional stock market two indices. A daily pattern in stock markets is observed for the two indices of West African Regional stock market return. We believe that our empirical results detecting significant and different daily patterns of mean returns and their volatility in West African Regional stock market return terms have useful implications for international portfolio diversification.

Finding certain patterns in volatility may be useful in several ways. For example investors may adjust their portfolios by increasing (reducing) their assets whose volatility is expected to reduce (increase). However, predictability and seasonality of stock returns found in this paper need not imply market inefficiency. Adjusting for transaction costs might eliminate any superior returns. One weakness of the study is that it does not consider individual share price rather it considers market index. So investment strategy on the basis of the finding of this study in case of individual share may not provide expected result.

But if the size of the portfolio is larger than closely represent the market then investment strategy on basis of the finding of this study is expected to provide some abnormal return to the investors. As the presence of the day of the week anomaly indicates inefficiency of the market, it informs the regulators and policy makers that appropriate measures should be taken to bring informational and operational efficiency in the market. It is argued by Islam and Gomes (1999) that a combination of factors like inadequate financial information, thin and discontinuous trading, reliance on price momentum as a basis for trading and manipulation by the market makers creates the conditions that lead to the positive weekend effect. Thus the regulators should take appropriate steps to remove such anomaly to bring the efficiency of the market. However, further research is needed involving other stock indices of west African regional stock market before making any firm conclusion in this regard.

\section{References}

Admati A.\& Pfleiderer. P. (1988). A theory of intraday patterns: Volume and price variability. Review of Financial Studies. 1.3-40

Aggrawal. R. \& Rivoli. P. (1989). Seasonal and day of the week effect in four emerging stock markets. Financial Review. 24. 541-550

Aggarwal, R. and Rivoli, P. (1989). "On the Relationship Between the United States' and Four Asian Equity Markets" Asean Economic Bulletin, 6, 110- 117.

Agrawal, A. and Tandon, K. (1994). Anomalies or illusions? Evidence from stock markets in eighteen countries, Journal of International Money and Finance, 13, 83-106.

Akgiray. V.(1989) conditional Hetereskedasticity in time series of stock returns: Evidence and forecasts. Journal of Business. 62. 55-80

Athanassakos. G. \& Robinson. M.J. (1994). The day of the week anomaly: the Toronto stock exchange experience. Journal of Business Finance and Accounting. 21. 833-856

Baillie. R.T. \& DeGennaro. R.P.(1990). Stock returns and volatility. Journal of Financial and Quantitative Analysis. 25. 203-214

Balaban Ercan. (1995). Day of the week effects : New evidence from an emerging market. Applied Economic Letters. 2. 139-143

Berument. H. \& Kiymaz. H. (2001). The day of the week effect on stock market volatility. Journal of Economics and Finance. 25. 181-193

Berument. H. \& Kiymaz. H. (2003), the day of the week effect on stock market volatility and volume: International Evidence. Review of Financial Economics (forthcoming)

Brooks, C., and Persand, G. (2001). "Seasonality in Southeast Asian Stock Markets: Some New Evidence on the day-of-the-week effects", Applied Economics Letters, 8(155), pp. 158.

Burton, M.G.(2003). "The Efficient Market Hypothesis and its Critics", Journal of Economic Perspectives, 17(1), pp. 59-82. 
Bourse Regional des Valeurs Mobilieres; Edition 2005-2006

Campbell. J.Y. \& Hentschel. L. (1992). No news is good news: An asymmetric model of changing volatility in stock returns. Journal of Financial Economics. 31. 281-318.

Cosimano. Thomas and Dennis Jansen. (1988). Estimates of the Variance of U.S. Inflation Based upon the ARCH Model: A Comment. Journal of Money. Credit. and Banking. 20(3). 409-21.

Chang. E.. Pinegar. M. \& Ravichandran. R. (1993). İnternational evidence on the robustness of the day of the week effect. Journal of Financial and Quantitative Analysis. 28.497-513.

Corhay. A.. Fatemi A. \& Rad A.T. (1995). On the presence of the day of the week effect in the foreign exchange market. Managerial Finance. 21.32-43

Coutts, J.A., and Sheikh, M.A.(2002). "The Anomalies that aren't there: the weekend, January and Pre-Holiday effects on the all Gold Index on the Johannesburg Stock Exchange 1987-1997”, Applied Financial Economics, 12, pp. 863-871.

Cross, F. (November/December 1973). "The Behavior of Stock Prices on Fridays and Mondays", Financial Analysts Journal, 67- 69.

Corhay. A.. \& Rad A.T. (1994). Statistical properties of daily returns: Evidence from European Stock Markets. Journal of Business Finance and Accounting. 21. 271- 282

Cosimano. T.F. \& Jansen. D.W. (1988). Estimates of the variance of US inflation based upon ARCH model. Journal of Money. Credit and Banking 20.409- 421

Cross. F. (1973). November-December) the behaviour of stock prices on Fridays and Mondays.Financial Analysis Journal.67-69

Dubois. M.L. (1986). the day of the week effect: the international evidence. Journal of Banking and Finance. 20. 1463-1484.

Engle, Robert F. (1992). Autoregressive Conditional Heteroscedasticity with Estimates of the Variance of United Kingdom Inflation." Econometrica 50, July, 987-1007.

Fama, E.F. (1965). The Behaviors of Stock Price. Journal of Business

Fama, E.F., and Roll, R. (1968). Some Properties of Symmetric Stable Distributions. Journal of the American Statistical Association.

Flannary. M.J. \& Protopapadakis. A.A. (1988). From T-bills to common stocks: investigating the generality of intra-week return seasonality. Journal of Finance.. 431-439.

Foster. F.D. \& Viswanathan. S. (1990). A theory of the interday variations in volume. variances and tarding cost: Evidence from recent price formulation models. Journal of Finance.48.187-211

French K. (1980). Stock returns and the weekend effect. Journal of Financial Economics. 8. 55-69.

French. K.R. \& Roll. R. (1986). stock return variances: the arrival ofinformation of reaction of traders. Journal of Financial Economics. 19. 3-30

French. K.. Schwert. G. \& Stambaugh. R. (1987). Expected stock returns and volatility. Journal of Financial Economics. 19.3-30

Gay.G. \& Kim. T. (1987). an investigation into seasonality in the futures market. Journal of the Futures Market.7. 169-181

Gesser. V.. \& Poncet. P. (1997). volatility patterns: theory and dome evidence from the dollar-mark option market. Journal of Derivatives. 5. 46-61.

Gibbons, M. and Hess, P. (October 1981). "Day of the Week Effects and Asset Returns", Journal of Business, 579596.

Gultekin and Gultekin. (1983). "Stock Market Seasonality: International Evidence"Journal of Financial Economics. $17-83$

Hamao. Y.. Masulis.R. \& Ng. V. (1990). Correlations in price changes and volatility across international stock markets. Review of Financial Studies. 3. 281-308.

Harvey. C.. \&Huang. R. (1991). Volatility in foreign exchange future markets. Review of Financial Studies. 4. 543-570. 
Hseish. D.A.(1988).the statistical properties of daily foreign exchange rates: 1974-1983. Journal of International Economics. 24. 129-145

Jaffe. J. \& Westerfield. R. (1985). the week-end effect in common stock returns : the international evidence: Journal of Finance. 40. 433-454.

Islam, M. M., \& Gomes J. L. (1999). The day-of -the-week effects in less-developed countries' markets: The case of Bangladesh. International Advances in Economic Research, 5(3), 397.

Karolyi. A.G. (1995). A multivariate GARCH model of international transmission of stock returns and volatility: the case of the united states and Canada. Journal of Business and Economic Statistics. 13.11-25.

Kato. K.. \& Schallheim. J.S. (1985). seasonal and size anomalies in the japanese stock market. Journal of Financial and Quantitative Analysis. 20. 243-260.

Keim. D.B..\&Stambaugh. F. (1984). A further investigation of weekend effects in stock returns. Journal of Finance. 39. $819-840$

Lakonishok. J.. \& Levi. M. (1982). weekend effect in stock return: a note. Journal of Finance. 37.883-889

Mehdian, Seyed, and Mark J. Perry. (1999). "An Analysis of the Monday Effect: Evidence from International Equity Markets," Journal of Research in Finance.

Mehdian, Seyed, and Mark J. Perry. (2001). "The Reversal of the Monday Effect: New Evidence from U.S. Equity Markets," Journal of Business Finance and Accounting.

Nelson. D.B. (1991). Conditional heteroskedasticity in asset returns: a new Approach. Econometrica. 59. 347-370.

Rogalski. R.J. (1984). New finfings regarding day of the week returns over trading and non-trading periods: A note. Journal of Finance. 35. 1603-1614.

Solnik. B.. \& Bousquet. L. (1990). day of the week effect on the paris bourse. Journal of Banking and Finance. 14. 461-468.

Theidossiou. P.. \& Lee. U. (1993). Mean and volatility spillovers across major national stock markets: further empirical evidence. Journal of Financial Research. 16. 337-350.

Table1. Average Daily returns over trading periods of 1998-2007, for the BRVM index and18 of its indices (All days are included)

\begin{tabular}{|c|cc|cc|}
\hline$I N D E X$ & \multicolumn{2}{|c|}{ BRVM_10 } & \multicolumn{2}{|c|}{ BRVM_COMPOSITE } \\
\hline B1 & 0.0161 & $(-0.8072)$ & 0.018 & $(-1.0419)$ \\
B2 & 0.0072 & $(-0.3035)$ & 0.0033 & $(0.1588)^{*}$ \\
B3 & 0.0032 & $(-0.1657)$ & 0.0038 & $(-0.2264)$ \\
B4 & 0.0228 & $(1.9468)^{*}$ & 0.0344 & $(1.6568)^{*}$ \\
B5 & 0.0357 & $(2.2504)^{* *}$ & 0.0194 & $(-1.168)$ \\
R Adj & -0.0012 & & -0.0011 & \\
F-value & 0.4192 & & 0.4297 & \\
P-value & 0.7949 & & 0.7873 & \\
DW & 1.8154 & & 1.6862 & \\
\hline
\end{tabular}

Note: 1. the Equity of means tests are based in the $\mathrm{R}_{t}=\sum_{i=1}^{5} B_{i} D_{i t}+\mu_{t}$, where $\mathrm{t}=1,2,3 \ldots \mathrm{N} . \mathrm{R}_{t}$ is the return from the index $\mathrm{i}$ on the day 1 .

$B_{1 t}=1$ for the day $\mathrm{j}$ and zero otherwise. $\mathrm{u}_{t}$ is the disturbance term

2. The values in parentheses denote the t-value of the coefficients. *, **, and *** denote statistical significance of given coefficients at $10 \%$, $5 \%$ and $1 \%$ respectively. 
Table 2. Daily Summary Statistics

\begin{tabular}{llllll}
\hline Index & Week 1 & Week 2 & Week 3 & Week 4 & Week 5 \\
\hline \hline & & & & & \\
Brvm_10 & & & & & \\
$\quad$ Mean & 0.0160 & 0.0076 & 0.0032 & 0.0227 & 0.0356 \\
Std. Dev. & 0.3811 & 0.3482 & 0.4347 & 0.4374 & 0.4726 \\
Skewness & -0.0464 & -0.5641 & -2.8069 & 0.3136 & -0.8231 \\
Kurtosis & 8.9852 & 10.7304 & 37.8557 & 8.2651 & 13.0828 \\
CV & 23.8680 & 45.8572 & 136.6627 & 19.2405 & 13.2678 \\
& & & & & \\
BRVM_Composite & & & & & \\
Mean & 0.0175 & 0.0026 & 0.0034 & 0.0338 & 0.0193 \\
Std. Dev. & 0.3500 & 0.2819 & 0.3609 & 0.3713 & 0.4154 \\
Skewness & 2.8840 & -0.5282 & -2.2034 & 1.9408 & -2.8477 \\
Kurtosis & 41.8133 & 11.8010 & 40.5953 & 18.6888 & 39.3702 \\
CV & 19.9771 & 109.3818 & 107.6145 & 10.9689 & 21.4903 \\
\hline
\end{tabular}

